\title{
Introducing Deep Eutetic Solvents to Polar Organometallic Chemistry: Chemoselective Addition of Organolithium and Grignard Reagents to Ketones under Air**
}

\author{
Cristian Vidal, ${ }^{a}$ Joaquín García-Álvarez, ${ }^{* a}$ Alberto Hernán-Gómez, ${ }^{b}$ Alan R. Kennedy, ${ }^{b}$ and Eva \\ Hevia $^{* b}$
}

Dedicated to Professor Bill Clegg on the occasion of his $65^{\text {th }}$ birthday

\begin{abstract}
Despite their enormous synthetic relevance, the use of polar organolithium and Grignard reagents is greatly limited by their requirements of low temperatures in order to control their reactivity as well as the need of dry organic solvents and inert atmosphere protocols to avoid their fast decomposition. Breaking new ground on the applications of these commodity organometallics in synthesis under more environmentally friendly conditions, this work introduces Deep Eutetic Solvents (DESs) as a green alternative media to carry out chemoselective additions of ketones under air at room temperature. Comparing their reactivities in DES with those observed in pure water suggest that a kinetic activation of the alkylating reagents is taking placing, favouring nucleophilic addition over the competitive hydrolysis, which can be rationalised through formation of halide-rich magnesiate or lithiate species.
\end{abstract}

$\boldsymbol{G}$ rignard and organolithium reagents are exceptionally valuable organometallic reagents in synthesis. Boasting extremely high reactivities, primarily due to the high polarity of their metal-carbon bonds, these reagents are indispensable to any laboratory where synthetic chemistry is carried out. ${ }^{[1]}$ Amongst their numerous applications, their addition reactions to ketones is one of the most versatile and fundamental methodologies to generate new $\mathrm{C}$-C bonds allowing access to tertiary alcohols. ${ }^{[2]}$ However, the chemoselectivity of these processes can be seriously compromised by formation of undesired reduction and/or enolization products, resulting from competing $\beta$-hydride elimination and deprotonation reactions respectively. ${ }^{[3]}$ Modern synthetic alternatives to overcome these

[*] C. Vidal, Dr. J. Garcia-Alvarez

Laboratorio de Compuestos Organometálicos y Catálisis (Unidad Asociada al CSIC)

Departamento de Química Orgánica e Inorgánica, Instituto

Universitario de Química Organometálica "Enrique Moles",

Facultad de Química, Universidad de Oviedo,

E-33071, Oviedo, Spain

E-mail: garciajoaquin@uniovi.es

Dr. Hernán-Gómez, Dr A. R. Kennedy, Prof. E. Hevia WestCHEM, Department of Pure and Applied Chemistry University of Strathclyde, Glasgow, UK, G1 1XL

E-mail: eva.hevia@strath.ac.uk

[**] Acknowledgements. We are indebted to MICINN of Spain (Projects CTQ2010-14796 and RYC-2011-08451) and the ERC. J. G.-A. thanks the MICINN and the European Social Fund for the award of a "Ramón y Cajal" contract. We also thank the Royal Society (University Research Fellowship to E. H.), and the European Research Council (ERC) for the generous sponsorship of this research. Authors thank Professor R. E. Mulvey for insightful discussions. unwanted side reactions include the use of inorganic salt additives (such as $\mathrm{CeCl}_{3}, \mathrm{FeCl}_{2}$ or $\mathrm{ZnCl}_{2}$ ), ${ }^{[4]}$ as well as the in situ generation of magnesiate $\left(\mathrm{LiMgR}_{3}\right)$ complexes by mixing Grignard reagents with alkyllithiums. ${ }^{[5]}$ Aiming to boost the nucleophilicity of these organometallic reagents, as well as activating the carbonyl substrates, most such approaches still require the restriction of low temperatures (ranging from 0 to $-78{ }^{\circ} \mathrm{C}$ ) to allow chemoselective control of the reaction. Furthermore, the use of dry ethereal solvents and inert atmosphere protocols is mandatory in order to avoid fast degradation of these polar reagents, which can react violently with air or moisture. These experimental constraints can greatly hamper their synthetic usefulness in scale-up industrial processes. Thus development of novel synthetic methodologies to use these reagents under more greener conditions, ${ }^{[6,7]}$ compatible with the presence of water and air, without having a detrimental effect in performance is the monumental challenge in polar organometallic chemistry.

Building new bridges between traditional polar organometallic synthesis and Green Chemistry, by pioneering the use of Grignard and organolithium reagents in Deep Eutectic Solvents (DESS), herein we report remarkable progress towards meeting this challenge which allows chemoselective alkylation of aliphatic and aromatic ketones to be conducted under air at room temperature and without the need of volatile organic solvents (VOCs).

$D E S s$ have emerged in synthesis as a new family of green solvents which find widespread applications in a variety of areas, spanning electrochemistry, biocatalysis, metal extraction, material chemistry, purification of biodiesel to metal-catalyzed organic reactions. ${ }^{[8]} \mathrm{DESS}$ are mostly obtained by mixing a quaternary ammonium salt with a hydrogen-bond donor that can form a complex with the halide anion of the ammonium salt. A popular choice to prepare DESs is the lowcost and readily available ammonium salt choline chloride $(\mathrm{ChCl}$, Fig 1), ${ }^{[9]}$ which in combination with biorenewable and environmentally benign hydrogen-bond donors [i.e. glycerol $(G l y)$, lactic acid $(L A)$, urea or water, Fig. 1] can form an eutectic mixture.

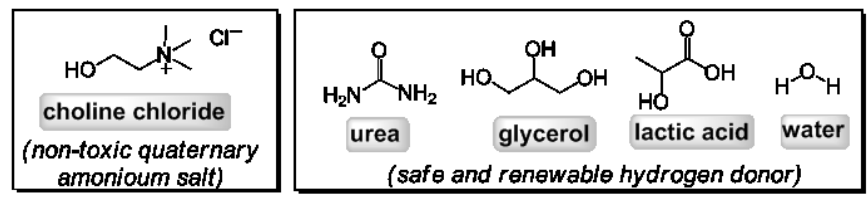

Figure 1. Components used in the synthesis of the DESs employed as solvent in this work.

To start this work addition of the Grignard reagent vinylmagnesium bromide to 2'-methoxy-acetophenone (1a) was examined at room temperature, under air, using different stoichiometries, (entries 1-3, 
Table 1) in the eutectic mixture $1 \mathrm{ChCl/2Gly.} \mathrm{Remarkably,} \mathrm{the} \mathrm{almost}$ instantaneous formation of the relevant tertiary alcohol 2a was observed in all cases, finding a significantly improved yield of $78 \%$ when 2 equivalents of the Grignard reagents were employed (entry 3 ). Replacing $G l y$ by other H-bond donors like ethylene glycol ( $E G$, entry 4 ) or water (entry 5) led to lower conversions. In all cases the formation of $\mathbf{2 a}$ occurs chemoselectively with no side products observed in the crude reaction mixture (only unreacted starting material 1a). Remarkably, when the reaction was carried out using water as a solvent, 2a was obtained in a diminished $21 \%$ yield, indicating that the addition reaction to $\mathbf{2 a}$ must be significantly slower under these conditions that with the $D E S$, which translates in a greater degree of hydrolysis of the organometallic reagent. ${ }^{[10]}$ Interestingly, using H-donors bearing carbonyl functionalities to generate the $D E S$ mixtures [urea (entry 6 ) or lactic acid ( $L A$, entry 7$)$ ] has a negative effect in the overall chemoselectivity of the addition process, yielding 2a in 67 and 30\% respectively, along with products generated by addition of Grignard reagent to the $\mathrm{C}=\mathrm{O}$ bond of these $\mathrm{H}$-donor molecules. ${ }^{[11]}$ Crucially the use of Schlenk techniques $\left(\mathrm{N}_{2}\right.$ or $\mathrm{Ar}$ atmosphere) or low temperatures $\left(0^{\circ} \mathrm{C}\right)$ is not required. In this sense and since $D E S S$ have high heat capacities, low temperatures are not needed to cool the reaction (but often mandatory for ethereal solvents). Although attempts to generate the Grignard reagent in the eutectic mixture $1 \mathrm{ChCl} / 2 \mathrm{Gly}$ failed, isolated vinylmagnesium bromide also reacts with the aromatic ketone 1a in the pure eutectic mixture (without ethereal co-solvents), although the yield is lower (60\%, entry 8 ) than when a commercial ethereal solution of the Grignard reagent was employed.

Table 1. Study of the addition reaction of vinylmagnesium bromide to 2'-methoxyacetophenone (1a) in different Deep Eutectic Solvents. ${ }^{a}$

\begin{tabular}{|c|c|c|c|}
\hline entry & Grignard $^{b}$ & Eutectic Mixture & Yield $(\%)^{c}$ \\
\hline 1 & $1 \mathrm{mmol}$ & $1 \mathrm{ChCl} / 2 \mathrm{Gly}$ & 20 \\
\hline 2 & $1.5 \mathrm{mmol}$ & $1 \mathrm{ChCl} / 2 \mathrm{Gly}$ & 43 \\
\hline 3 & $2 \mathrm{mmol}$ & $1 \mathrm{ChCl} / 2 \mathrm{Gly}$ & 78 \\
\hline 4 & $2 \mathrm{mmol}$ & $1 \mathrm{ChCl} / 2 \mathrm{EG}$ & 55 \\
\hline 5 & $2 \mathrm{mmol}$ & $1 \mathrm{ChCl} / 2 \mathrm{H}_{2} \mathrm{O}$ & 57 \\
\hline $6^{c}$ & $2 \mathrm{mmol}$ & $1 \mathrm{ChCl} / 2$ Urea & 67 \\
\hline $7^{d}$ & $2 \mathrm{mmol}$ & $1 C h C l / 2 L A$ & 30 \\
\hline $8^{e}$ & $2 \mathrm{mmol}$ & $1 \mathrm{ChCl} / 2 \mathrm{Gly}$ & 60 \\
\hline
\end{tabular}

a Reactions done under air, at room temp. using $1 \mathrm{~g}$ of DES. Reaction time $2-3$ seconds. $1 \mathrm{mmol}$ of the ketone used. ${ }^{b} \mathrm{~A}$ commercially available $1.0 \mathrm{M}$ solution of vinylmagnesium bromide in THF was used. ${ }^{c}$ Determined by $\mathrm{GC}$ and ${ }^{1} \mathrm{H}$ NMR. ${ }^{d}$ Addition of Grignard reagent to Urea or $L A$ was also seen. ${ }^{e}$ Ethereal solvent removed by exhaustive evacuation.

Encouraged by these initial findings, which glimpse the potential that $1 \mathrm{ChCl} / 2 \mathrm{Gly}$ and $1 \mathrm{ChCl} / 2 \mathrm{H}_{2} \mathrm{O}$ have as green solvents for the chemoselective addition of Grignard reagents to ketones under standard bench experimental techniques, we then assessed the scope of this methodology extending our studies to a range of Grignard reagents with both aromatic and aliphatic ketones (Table 2). Similarly to the experiments compiled in Table 1, the addition reactions in both eutectic mixtures were completed in exceptionally short reaction times (2-3 seconds), with in most cases a high degree of selectivity, recovering only unreacted ketone. An exception was the reaction of $\mathrm{EtMgCl}$ with benzophenone (1b) (entries 7 and 8, Table 2) where the corresponding reduction product (diphenylmethanol, 3) was also formed (vide infra). ${ }^{[12]}$ Considering first the two different eutectic mixtures employed, although no direct correlation was found between the H-bond donor component of the DESS (Gly or water) and the outcome of the reaction, in general, better yields for the corresponding alcohols $\mathbf{2}$ were obtained in the Gly-containing eutectic mixture (odd entries in Table 2). Using vinylmagnesium bromide as an alkenylating reagent tertiary alcohols $\mathbf{2 a}, \mathbf{2 c}$ and $\mathbf{2 e}$ can be effectively obtained from reactions with 2 '-methoxy-acetophenone (1a) (entries 1 and 2), benzophenone (1b) (entries 5 and 6) and aliphatic ketone 2-pentanone (1c) (entries 9 and 10) respectively. Similarly ethynylmagnesium bromide reacts with $\mathbf{1 a}$, affording $\mathbf{2} \mathbf{f}$ in a 77 and a $72 \%$ yield depending on the eutectic mixture employed (entries 11 and 12). Confronting the same ketone with $\mathrm{EtMgCl}$, where $\beta$-hydride transfer (reduction) is more plausible, led exclusively to addition product $\mathbf{2 b}$ in 64 and $73 \%$ yields (entries 3 and 4 using $1 \mathrm{ChCl} / 2 \mathrm{Gly}$ and $1 \mathrm{ChCl} / 2 \mathrm{H}_{2} \mathrm{O}$ ), although when benzophenone was employed, secondary alcohol $\mathbf{3}$ was the major product (entries 7 and 8, Table 2), while ethyl adduct $\mathbf{2 d}$ was obtained in modest yields, similar to those previously reported for the same reaction using dry THF as solvent at $0{ }^{\circ} \mathrm{C} .{ }^{[4 c]}$

Table 2. Addition of various Grignard reagents to ketones 1a-1c in $\mathrm{ChCl}$-based eutectic mixtures. ${ }^{a}$

$$
\underset{\text { 1a-c }}{\mathrm{R}^{1}} \stackrel{\text { DESs }}{\mathrm{R}^{2}}+2 \mathrm{R}^{3} \mathrm{MgBr} \underset{\text { rt, under air }}{\mathrm{R}^{1}}
$$

${ }^{a}$ Reactions performed under air, at room temperature using $1 \mathrm{~g}$ of the DES Reaction time: 2-3 seconds. $1 \mathrm{mmol}$ of ketone used. Commercially available 1.0

\begin{tabular}{ccccccc}
\hline entry & $\mathrm{R}^{1}$ & $\mathrm{R}^{2}$ & $\mathrm{R}^{3}$ & \multicolumn{2}{c}{$\mathrm{DES}$} & \multicolumn{2}{c}{ Yield $(\%)$} & of $\mathbf{2}^{b}$ \\
\hline 1 & $\mathrm{o}-(\mathrm{MeO}) \mathrm{C}_{6} \mathrm{H}_{4}$ & $\mathrm{Me}$ & vinyl & $1 \mathrm{ChCl} / 2 \mathrm{Gly}$ & $\mathbf{2 a}$ & 78 \\
2 & $\mathrm{o}-(\mathrm{MeO}) \mathrm{C}_{6} \mathrm{H}_{4}$ & $\mathrm{Me}$ & vinyl & $1 \mathrm{ChCl} / 2 \mathrm{H}_{2} \mathrm{O}$ & $\mathbf{2 a}$ & 57 \\
3 & $\mathrm{o}-(\mathrm{MeO}) \mathrm{C}_{6} \mathrm{H}_{4}$ & $\mathrm{Me}$ & $\mathrm{Et}$ & $1 \mathrm{ChCl} / 2 \mathrm{Gly}$ & $\mathbf{2 b}$ & 64 \\
4 & $\mathrm{o}-(\mathrm{MeO}) \mathrm{C}_{6} \mathrm{H}_{4}$ & $\mathrm{Me}$ & $\mathrm{Et}$ & $1 \mathrm{ChCl} / 2 \mathrm{H}_{2} \mathrm{O}$ & $\mathbf{2 b}$ & 73 \\
5 & $\mathrm{Ph}$ & $\mathrm{Ph}$ & vinyl & $1 \mathrm{ChCl} / 2 \mathrm{Gly}$ & $\mathbf{2 c}$ & 69 \\
6 & $\mathrm{Ph}$ & $\mathrm{Ph}$ & vinyl & $1 \mathrm{ChCl} / 2 \mathrm{H}_{2} \mathrm{O}$ & $\mathbf{2 c}$ & 44 \\
$7^{\mathrm{c}}$ & $\mathrm{Ph}$ & $\mathrm{Ph}$ & $\mathrm{Et}$ & $1 \mathrm{ChCl} / 2 \mathrm{Gly}$ & $\mathbf{2 d}$ & $24[46]$ \\
$8^{\mathrm{c}}$ & $\mathrm{Ph}$ & $\mathrm{Ph}$ & $\mathrm{Et}$ & $1 \mathrm{ChCl} / 2 \mathrm{H}_{2} \mathrm{O}$ & $\mathbf{2 d}$ & $19[46]$ \\
9 & $\mathrm{CH}_{3}\left(\mathrm{CH}_{2}\right)_{2}$ & $\mathrm{Me}$ & vinyl & $1 \mathrm{ChCl} / 2 \mathrm{Gly}$ & $\mathbf{2 e}$ & 79 \\
10 & $\mathrm{CH}_{3}\left(\mathrm{CH}_{2}\right)_{2}$ & $\mathrm{Me}$ & vinyl & $1 \mathrm{ChCl} / 2 \mathrm{H}_{2} \mathrm{O}$ & $\mathbf{2 e}$ & 87 \\
11 & $\mathrm{o}-(\mathrm{MeO}) \mathrm{C}_{6} \mathrm{H}_{4}$ & $\mathrm{Me}$ & ethynyl & $1 \mathrm{ChCl} / 2 \mathrm{Gly}$ & $\mathbf{2 f}$ & 77 \\
12 & $\mathrm{o}-(\mathrm{MeO}) \mathrm{C}_{6} \mathrm{H}_{4}$ & $\mathrm{Me}$ & ethynyl & $1 \mathrm{ChCl} / 2 \mathrm{H}_{2} \mathrm{O}$ & $\mathbf{2 f}$ & 72 \\
\hline
\end{tabular}

$\mathrm{M}$ solutions of the relevant Grignard reagents in THF $(2 \mathrm{mmol})$ were employed ${ }^{b}$ Determined by GC and ${ }^{1} \mathrm{H}$ NMR. ${ }^{c}$ Formation of diphenylmethanol (3), resulting from the reduction reaction was also observed, with yields displayed in brackets.

Theoretical and experimental studies monitoring the addition reactions of carbonyl compounds by Grignard reagents, using neat water as a solvent, have shown that while for allyl Grignard reagents additions take place at a comparable rate to those of the competing hydrolysis processes, ${ }^{[10]}$ alkyl analogues, such as $\mathrm{BuMgCl}$, are much more kinetically retarded (addition reaction is up to $10^{5}$ times slower),${ }^{[13]}$ and therefore protonation occurs preferentially, yielding only trace amounts of addition products. This behaviour contrasts sharply with the reactions mentioned above with $\mathrm{EtMgCl}$ and 1a where in both eutectic mixtures $\left(1 \mathrm{ChCl} / 2 \mathrm{Gly}\right.$ and $\left.1 \mathrm{ChCl} / 2 \mathrm{H}_{2} \mathrm{O}\right)$, the tertiary alcohol $\mathbf{2 b}$ is the major product (entries 3 and 4 table 2), hinting at some type of kinetic activation of the Grignard reagent may be occurring using the $D E S$ s. Furthermore in this case the conversions observed for $\mathbf{2 b}$ are greater than that found when $\mathbf{1 a}$ is reacted at -78 ${ }^{\circ} \mathrm{C}$ in dry THF under strictly inert atmosphere techniques $(45 \%)$. Germane to this work, Song has recently shown that catalytic amounts of ammonium salt $\mathrm{NBu}_{4} \mathrm{Cl}$ in THF solutions of Grignard reagents can greatly enhance the chemoselectivity of addition reactions, minimizing formation of enolization and reduction products. ${ }^{[14]}$ The authors proposed that substoichiometric amounts of the salt can shift the position of the Schlenk equilibrium of Grignard reagents to form dinuclear $\mathrm{R}_{2} \mathrm{Mg}$. $\mathrm{MgX}_{2}$ species which would favour addition. Since a main component in the eutectic mixtures employed in this work is an ammonium salt, a related activation effect can be operative. To explore this possibility more, we reacted choline chloride $(\mathrm{ChCl})$ with various amounts of the Grignard reagent 
$\mathrm{Me}_{3} \mathrm{SiCH}_{2} \mathrm{MgCl}$ in THF solvent. However, due to poor solubility of this ammonium salt in this organic solvent, no reaction was observed. In contrast, the addition of one equivalent of Grignard to the slightly more soluble $\mathrm{NBu}_{4} \mathrm{Cl}$ afforded a solution that deposited crystals of magnesiate $\left[\left\{\mathrm{NBu}_{4}\right\}^{+}\left\{(\mathrm{THF}) \mathrm{MgCl}_{2}\left(\mathrm{CH}_{2} \mathrm{SiMe}_{3}\right)\right\}^{-}\right]$(4) in a $87 \%$ yield.

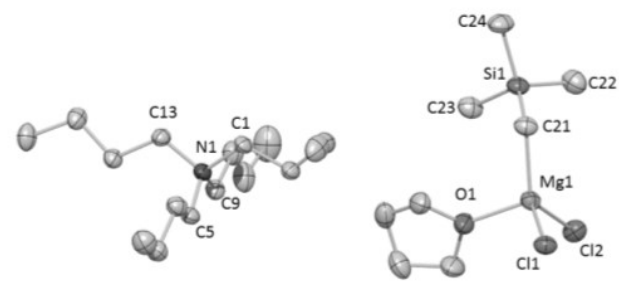

Figure 2 Molecular structure of 4 . Displacement ellipsoids are drawn at the $50 \%$ probability level. Hydrogen atoms have been omitted for clarity

X-ray crystallographic studies established that the molecular structure of 4 (Fig. 2) is surprisingly a monomer, comprising a well-defined magnesiate anion, made up of a $\mathrm{Mg}$ atom which binds terminally to an alkyl group, two chlorines and a THF molecule, and a tetrabutylamonium counterion. ${ }^{1} \mathrm{H}$ DOSY NMR studies on solutions of $\mathbf{4}$ in $\mathrm{d}_{8}$-THF confirmed that this structure is retained. These results suggest that these activating effects of the ammonium salts in THF solutions may be best rationalized in terms of the formation of an anionic 'ate species which should have an enhanced nucleophilic power over that of a neutral Grignard reagent. The use of highly reactive magnesiate species as chemoselective reagents for additions to ketones has been previously described, but as far as we are aware, this involves the in situ formation of a bimetallic reagent, by cocomplexation of the Grignard reagent with an organolithium. ${ }^{[5]}$ These lithium magnesiates exhibit greater kinetic reactivities and unique selectivity profiles, unmatched by conventional magnesium reagents. ${ }^{[15]}$. Although the formation of a similar compound to $\mathbf{4}$ using ammonium salt $\mathrm{ChCl}$ present in the DESs employed in this work could not be demonstrated, the possibility of the participation of more nucleophilic magnesiate species in the addition reactions described in Tables 1 and 2 cannot be disregarded. This would imply that $\mathrm{ChCl}$ may have a double role in these processes, as a component of the $D E S$ mixture employed but also as part of organometallic alkylating reagent, being a halide source.

To probe the scope of DESs in terms of the nature of the polar organometallic reagent employed we then studied the reactivity of ketones 1a-c with a series of organolithium reagents (Table 3 ). The large increase in the polarity of the metal-carbon bonds in these commodity reagents when compared with organomagnesium compounds, generally imposes the use of much lower temperatures in order to control their selectivity. ${ }^{[1]}$ Thus, for example the addition of BuLi to acetophenone should be performed at $-78^{\circ} \mathrm{C}$ in THF, and even so the tertiary alcohol is obtained in a $62 \%$ yield along with $7 \%$ yield of the unwanted aldol condensation product. ${ }^{[5]}$ Contrastingly, under the previously optimized reaction conditions used for Grignard reagents ( $\mathrm{ChCl}$-based eutectic mixtures as solvent, at room temperature under air; Table 3), BuLi can be added instantaneously to 2-methoxy-acetophenone (1a) to give tertiary alcohol $\mathbf{2 g}$ in impressive yields $(60-82 \%$, entries $1,2,3)$ without forming any other by-products. We believe this makes our study unique in that it is the first to report the successful coexistence of organolithium reagents and green solvents within the same solution. Again and as previously demonstrated for Grignard reagents, the addition reaction of BuLi is orders of magnitude faster than its protonation by water, ethylene glycol or glycerol present in the DES. Showing the general applicability of this approach, chemoselective butylation was also observed for the exclusively aliphatic ketone 1c (entries 6-7, table 3) in either Gly-or water-containing eutectic mixtures. Diverging from the low conversions observed in the reactions of $\mathrm{EtMgCl}$ with benzophenone (1b) (entries 7 and 8 in Table 2), the addition of BuLi to this sensitive ketone formed the relevant tertiary alcohol $\mathbf{2 h}$ in much greater yields, although small amounts of reduction product 3 could also be detected in reaction mixtures (entries 4 and 5 in Table $3)$. Besides aliphatic ones, aromatic organolithium reagents $(\mathrm{PhLi})$ can also be successfully added to both aromatic (entries 8-11, Table 3 ) and aliphatic (entries 12-13, Table 3) substrates. ${ }^{[12]}$ Trying to push our system to its limits, the commercially available solid lithium acetylide ethylenediamine complex (without organic solvent) was added to the reaction mixture containing the water-based $D E S$ $1 \mathrm{ChCl} / 2 \mathrm{H}_{2} \mathrm{O}$ and 2-pentanone (entry 14, Table 3). Astonishingly, almost quantitative (84\%) formation of the desired propargylic alcohol was seen, confirming that addition can be also performed in pure eutectic mixtures. It should be noted that the same reaction tested using $\mathrm{H}_{2} \mathrm{O}$ as a solvent gave ketone $\mathbf{2 m}$ in a modest $7 \%$ yield, which hints at a possible activation effect of the organolithium reagent when it is added to the $D E S$ mixtures.

Table 3. Addition of organolithium (RLi) reagents to ketones $1 \mathrm{a}-1 \mathrm{c}$ in $\mathrm{ChCl}$ based eutectic mixtures. ${ }^{a}$

\begin{tabular}{|c|c|c|c|c|c|c|}
\hline entry & $\mathrm{R}^{1}$ & $\mathrm{R}^{2}$ & $\mathrm{R}^{3}$ & $D E S$ & \multicolumn{2}{|c|}{ Yield $(\%)$ of $\mathbf{2}^{b}$} \\
\hline 1 & $o-(\mathrm{MeO}) \mathrm{C}_{6} \mathrm{H}_{4}$ & $\mathrm{Me}$ & $\mathrm{Bu}$ & $1 \mathrm{ChCl} / 2 \mathrm{Gly}$ & $2 \mathrm{~g}$ & $71^{e}$ \\
\hline 2 & $\mathrm{o}-(\mathrm{MeO}) \mathrm{C}_{6} \mathrm{H}_{4}$ & $\mathrm{Me}$ & $\mathrm{Bu}$ & $1 \mathrm{ChCl} / 2 \mathrm{H}_{2} \mathrm{O}$ & $2 g$ & 82 \\
\hline 3 & $\mathrm{o}-(\mathrm{MeO}) \mathrm{C}_{6} \mathrm{H}_{4}$ & $\mathrm{Me}$ & $\mathrm{Bu}$ & $1 C h C l / 2 E G$ & $2 g$ & 60 \\
\hline $4^{c}$ & $\mathrm{Ph}$ & $\mathrm{Ph}$ & $\mathrm{Bu}$ & $1 \mathrm{ChCl} / 2 \mathrm{Gly}$ & $2 h$ & $75(12)$ \\
\hline $5^{c}$ & $\mathrm{Ph}$ & $\mathrm{Ph}$ & $\mathrm{Bu}$ & $1 \mathrm{ChCl} / 2 \mathrm{H}_{2} \mathrm{O}$ & $2 \mathrm{~h}$ & $68(9)$ \\
\hline 6 & $\mathrm{CH}_{3}\left(\mathrm{CH}_{2}\right)_{2}$ & $\mathrm{Me}$ & $\mathrm{Bu}$ & $1 \mathrm{ChCl} / 2 \mathrm{Gly}$ & $2 \mathbf{i}$ & 73 \\
\hline 7 & $\mathrm{CH}_{3}\left(\mathrm{CH}_{2}\right)_{2}$ & $\mathrm{Me}$ & $\mathrm{Bu}$ & $1 \mathrm{ChCl} / 2 \mathrm{H}_{2} \mathrm{O}$ & $2 \mathbf{i}$ & 85 \\
\hline 8 & $o-(\mathrm{MeO}) \mathrm{C}_{6} \mathrm{H}_{4}$ & $\mathrm{Me}$ & $\mathrm{Ph}$ & $1 \mathrm{ChCl} / 2 \mathrm{Gly}$ & $2 \mathrm{j}$ & 80 \\
\hline 9 & $O-(\mathrm{MeO}) \mathrm{C}_{6} \mathrm{H}_{4}$ & $\mathrm{Me}$ & $\mathrm{Ph}$ & $1 \mathrm{ChCl} / 2 \mathrm{H}_{2} \mathrm{O}$ & $2 \mathbf{j}$ & 82 \\
\hline 10 & $\mathrm{Ph}$ & $\mathrm{Ph}$ & $\mathrm{Ph}$ & $1 \mathrm{ChCl} / 2 \mathrm{Gly}$ & $2 k$ & 81 \\
\hline 11 & $\mathrm{Ph}$ & $\mathrm{Ph}$ & $\mathrm{Ph}$ & $1 \mathrm{ChCl} / 2 \mathrm{H}_{2} \mathrm{O}$ & $2 k$ & 85 \\
\hline 12 & $\mathrm{CH}_{3}\left(\mathrm{CH}_{2}\right)_{2}$ & $\mathrm{Me}$ & $\mathrm{Ph}$ & $1 \mathrm{ChCl} / 2 \mathrm{Gly}$ & 2I & 72 \\
\hline 13 & $\mathrm{CH}_{3}\left(\mathrm{CH}_{2}\right)_{2}$ & $\mathrm{Me}$ & $\mathrm{Ph}$ & $1 \mathrm{ChCl} / 2 \mathrm{H}_{2} \mathrm{O}$ & 2I & 90 \\
\hline $14^{d}$ & $\mathrm{CH}_{3}\left(\mathrm{CH}_{2}\right)_{2}$ & $\mathrm{Me}$ & ethynyl & $1 \mathrm{ChCl} / 2 \mathrm{H}_{2} \mathrm{O}$ & $2 m$ & 84 \\
\hline
\end{tabular}

${ }^{a}$ Reactions performed under air, at room temperature using $1 \mathrm{~g}$ of the $D E S$. Reaction time; 2-3 seconds. $1 \mathrm{mmol}$ of ketone used. Commercially available 1.6 $\mathrm{M}$ solution in hexane of BuLi and $1.8 \mathrm{M}$ solution in dibutylether of $\mathrm{PhLi}(2 \mathrm{mmol}$ in all cases) were employed. ${ }^{b}$ Determined by GC and ${ }^{1} \mathrm{H}$ NMR. ${ }^{c}$ Formation of the reduction product 3 was also observed. ${ }^{d}$ Lithium acetylide ethylenediamine

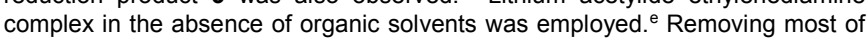
the hexane under vacuum from the commercial BuLi solution did not affect the selectivity of the addition reaction although $\mathbf{2 g}$ was obtained in a slightly lower yield $(66 \%)$.

To assess the possibility of forming a lithiate complex with ammonium salts, similar investigations to those mentioned for Grignard reagents were carried out. Supporting the formation of a complex, the addition of one molar equivalent of $\mathrm{LiCH}_{2} \mathrm{SiMe}_{3}$ to a $\mathrm{NBu}_{4} \mathrm{Cl}$ suspension in THF gave a solution which on cooling deposited colourless crystals which melt very quickly about $-10{ }^{\circ} \mathrm{C}$, precluding their analysis by X-ray crystallography. Multinuclear $\left({ }^{1} \mathrm{H}\right.$, ${ }^{13} \mathrm{C}$ and ${ }^{7} \mathrm{Li}$ ) magnetic resonance investigations of this solid in $\mathrm{d}_{8}$ - THF solution supports the formation of a new species (see Supporting Information). Although the chemical shifts observed for the resonances for the $\mathrm{Li}-\mathrm{CH}_{2}$ group in ${ }^{1} \mathrm{H}$ and ${ }^{13} \mathrm{C}$ NMR spectra do not differ significantly to those found for $\mathrm{LiCH}_{2} \mathrm{SiMe}_{3}$ in the same deuterated solvent, there is a distinct change for that seen in ${ }^{7} \mathrm{Li} \mathrm{NMR}$ spectra, moving from $3.54 \mathrm{ppm}$ in the organolithium precursor to 0.61 $\mathrm{ppm}$ in the crystalline product, which is consistent with a marked change in the metal coordination sphere. Interestingly, the integration 
of the ammonium butyl groups against the monosilyl group revealed a 2:1, $\mathrm{NBu}_{4}: \mathrm{CH}_{2} \mathrm{SiMe}_{2}$ ratio which would be consistent with forming a dianionic halolithiate $\left[\left\{\mathrm{NBu}_{4}\right\}_{2}{ }^{+}\left\{\mathrm{LiCl}_{2}\left(\mathrm{CH}_{2} \mathrm{SiMe}_{3}\right)\right\}^{2-}\right]$, where two $\mathrm{Cl}$ anions have been transferred to lithium. It should be noted that the addition of $\mathrm{LiCl}$ to lithium amides or organolithium reagents has a profound effect on their reactivity. Thus kinetic studies have shown that by adding less that $1 \mathrm{~mol} \%$ of $\mathrm{LiCl}$ to lithium diisopropylamide, its 1,4-addition reaction to unsaturated ethers occurs 70 times faster. ${ }^{[16]}$ A similar halide-mediated accelerating effect could also favour the addition reaction in $D E S$ over the competing protonation process.

In summary, this work introduces Deep Eutectic Solvents as superior green and biorenewable reaction media for highly polar organometallic compounds. As illustrated with both Grignard and organolithium reagents, these eutectic mixtures are the solvents of choice to cross the frontiers between synthetically useful main group chemistry and green solvents. A comparison of the reactivity profiles of these reagents in DESs mixtures with those in pure water, suggest that a kinetic activation of the alkylating reagents occurs in the former, favouring nucleophilic addition over the competing hydrolysis process. Building on recent work on the enhanced reactivity of Grignard reagents on the addition of ammonium salts, a plausible rationale may be the in situ formation of anionic halide-rich magnesiate or lithiate species. Clearly, this first crossing opens up a new, much sought after frontier of organolithium chemistry in their practical application under environmentally-friendly conditions (green solvents, room temperature and in the presence of air).

\section{Experimental Section}

Full experimental details are included in Supporting Information. CCDC-978224 (4) contains the supplementary crystallographic data for this paper. These data can be obtained free of charge from The Cambridge Crystallographic Data Centre via www.ccdc.cam.ac.uk/data request/cif.

Received: ((will be filled in by the editorial staff))

Published online on ((will be filled in by the editorial staff))

Keywords: Deep Eutectic Solvents • Organolithium - Grignard reagents $•$ Green Chemistry $\cdot$ Ate Chemistry •Addition Reactions
Organolithiums: Selectivity for Synthesis. Pergamon, Elsevier Science Ltd., Oxford, UK, 2002.

[2] For selected references see: (a) S. E. Denmark, J. Fu, Chem. Rev. 2003, 103, 2763. (b) H. Li, P. Walsh, J. Am. Chem. Soc. 2005, 127, 8355. (c) M. Hatano, T. Miyamoto, K. Ishihara, Curr. Org. Chem. 2006, 10, 1849. (d) M. Hatano, S. Suzuki, K. Ishihara, Synlett, 2010, 321

[3] S. Yamazaki, S. Yamabe, J. Org. Chem. 2002, 67, 9346.

[4] (a) T. Imamoto, Y. Sugiyura, T. Takiyama, T. Hatojima, Y. Kamiya, J. Am. Chem. Soc. 1989, 111, 4392. (b) A. Krasovskiy, F. Kopp, P. Knochel, Angew. Chem. 2006, 118, 511; Angew. Chem. Int. Ed. 2006, 45, 497. (c) M. Hatano, S. Suzuki, K. Ishihara, J. Am. Chem. Soc. 2006, 128, 9998. (d) M. Hatano, O. Ito, S. Suzuki, K. Ishihara, Chem. Commun. 2010, 46, 2674. (e) M. Hatano, O. Ito, S. Suzuki, K. Ishihara, J. Org. Chem. 2010, 75, 5008.

[5] M. Hatano, T. Matsumura, K. Ishihara, Org. Lett. 2005, 7, 573.

[6] For a recent study using 2-methyltetrahydrofuran as a greener alternative to conventional ethereal solvents see: A. Kadam, M. Nguyen, M. Kopach, P. Richardson, F. Gallou, Z. K. Wan, W. Zhang, Green Chem. 2013, 15, 1880.

[7] Solvents are responsible of most of the waste generated in the chemical industries and laboratories. D. J. C. Constable, C. Jiménez-González, R. K. Henderson. Org. Process Res. Dev. 2007, 11, 133.

[8] For selected reviews in the area see: (a) A. P. Abbott, R. C. Harris, K. Ryder, C. D'Agostino, L. Gladden, M. D. Mantle, Green Chem. 2011, 13, 82. (b) C. Ruß, B. König, Green Chem. 2012, 14, 2969. (c) Q. Zhang, K. De Oliveira Vigier, S. Royer, F. Jérôme, Chem. Soc. Rev. 2012, 41, 7108. (d) Y. Gu, F. Jérôme, Chem. Soc. Rev. 2013, 42, 9550.

[9] M. Petkovic, J. L. Ferguson, H. Q. N. Gunaratne, R. M. Ferreira, C. Leitão, K. R. Seddon, L. P. N. Rebelo, C. S. Pereira, Green. Chem. 2010 $12,643$.

[10] G. Osztrovszky, T. Holm, R. Madsen, Org. Biomol. Chem. 2010, 8, 3402 .

[11] It has been previously described that the urea contained in different eutectic mixtures can be not only a constituent of the solvent but also participate as a reactant. For recent examples see reference 8 .

[12] Aromatic alcohols derived from benzophenone can be separated from the reaction media by simple addition of water to the reaction crude, allowing their precipitation which can then be isolated by filtration, without the need of organic solvents.

[13] T. Holm, J. Org. Chem. 2000, 657, 1188.

[14] H. Zong, H. Huang, J. Liu, G. Bian, L. Song, J. Org. Chem. 2012, 77, 4645 .

[15] (a) R. E. Mulvey, Dalton Trans. 2013, 42, 6676. (b) A. HarrisonMarchand, F. Mongin, Chem. Rev. 2013, 113, 7470.

[16] Y. Ma, A. C. Hopeker, L. Grupta, M. F. Faggin, D. B. Collum, J. Am. Chem. Soc. 2010, 132, 1561.

[1] (a) The Chemistry of Organomagnesium Compounds, Z. Rappoport, I. Marek, Eds., Patai Series, Wiley, Chichester, UK, 2008 (b) J. Clayden, 


\section{Angewandte

Entry for the Table of Contents (Please choose one layout)

Layout 2:

\section{Green Chemistry}

Cristian Vidal, Joaquín García-Álvarez, * Alberto Hernán-Gómez, Alan R. Kennedy, and Eva Hevia*

$$
\text { Page - Page }
$$

Introducing Deep Eutetic Solvents to Polar Organometallic Chemistry:

Chemoselective Addition of Organolithium and Grignard Reagents to Ketones under Air.

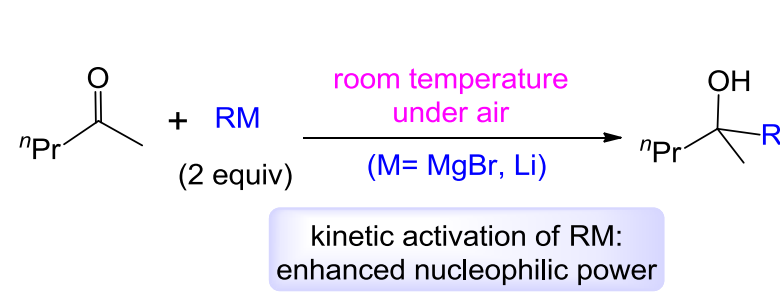

Deep Eutectic Solvent $\left(1 \mathrm{ChCl} / 2 \mathrm{H}_{2} \mathrm{O}\right)$ excellent yields (79-90\%) neat $\mathrm{H}_{2} \mathrm{O}$ hydrolysis of RM, yields below $10 \%$

Turning lithium green: A new protocol for the selective addition of Grignard and organolithium reagents to ketones in green and biorenewable Deep Eutectic Solvents (DESs) at room temperature and under air is reported, establishing a bridge between main-group organometallic compounds and Green Solvents. 